\title{
Policiamento e gênero: percepções entre policiais militares paranaenses ${ }^{1}$
}

\author{
Cleber da Silva Lopes ${ }^{2}$ (i) \\ Ednaldo Aparecido Ribeiro ${ }^{3}$ \\ Marcos Aparecido de Souza ${ }^{4}$ (i)
}

\begin{abstract}
A integração feminina à polícia vem encontrando obstáculos decorrentes do modo como policiais representam o policiamento e o papel que homens e mulheres deveriam desempenhar dentro dele. Este artigo pretende contribuir para o entendimento da natureza dessas representações e obstáculos. Ser homem ou mulher condiciona a percepção de que força física e coragem são atributos fundamentais para o policiamento? Influencia a visão segundo a qual os policiais masculinos são mais preparados para as atividades operacionais e as policiais femininas têm mais afinidade com as atividades de cuidado e assistência? $\mathrm{O}$ artigo analisa essas questões por meio de análise quantitativa de dados de uma pesquisa de survey realizada em 2012 na Polícia Militar do Paraná. Os dados indicam que homens e mulheres concordam igualmente com a visão de que o policiamento é uma atividade que demanda força física e coragem, mas mantêm perspectivas distintas sobre quem é mais apto a atuar nas atividades operacionais. Esses resultados sugerem dificuldades consideráveis para a integração das mulheres às atividades operacionais da polícia.

Palavras-chave: gênero; Polícia Militar; percepções; pesquisa de survey; Paraná
\end{abstract}

\section{Introdução}

A presença feminina em organizações policiais é um fenômeno relativamente recente. Embora a polícia seja uma criação do século XIX, a incorporação das mulheres ao policiamento ocorreu apenas no século seguinte. As primeiras nomeações foram realizadas nos EUA em 1908, mas a expansão da presença feminina na polícia nas democracias antigas ocorreu somente nas décadas subsequentes sob o impulso de três fatores: a

\footnotetext{
${ }^{1}$ Gostaríamos de agradecer a Martha Célia Ramirez Galvez e Silvana Aparecida Mariano pelos comentários e sugestões feitas em uma versão preliminar deste artigo. Todas as afirmações são de nossa responsabilidade.

2 Universidade Estadual de Londrina, Departamento de Ciências Sociais. Laboratório de Estudos sobre Governança da Segurança da UEL. Londrina (PR), Brasil. E-mail: <clopes@uel.br>.

3 Universidade Estadual de Maringá (UEM), Departamento de Ciências Sociais. Maringá (PR), Brasil.

E-mail: <ednaldoribeiro@icloud.com>.

4 Polícia Militar do Paraná (PMPR). Foz do Iguaçu (PR), Brasil. E-mail: <tenentemeracos@yahoo.com.br>.
} 
necessidade de preencher lacunas deixadas pelos homens durante períodos de guerra; a realização de reformas institucionais para enfrentar problemas como corrupção, violência, deterioração da imagem e perda de credibilidade da polícia; e pressões sociais decorrentes de movimentos feministas (Brown, 1997; Prenzler e Sinclair, 2013). No Brasil, a incorporação das mulheres à polícia é muito mais recente. A maioria das forças policiais brasileiras responsáveis pelo policiamento ostensivo admitiu a entrada de mulheres em seus quadros somente a partir do final da década de 1970, com o objetivo de melhorar a imagem da polícia, naquele momento fortemente associada à ditatura militar e à repressão (Soares e Musumeci, 2005; Moreira e Wolff, 2009) 5 .

Apesar da incorporação tardia, o Brasil tinha, em meados da década de 2010, cerca de 73 mil mulheres empregadas nas polícias militares e civis, algo próximo a $13 \%$ do efetivo total dessas organizações (FBSP, 2015). Trata-se de um percentual superior ao encontrado nos EUA $(11,8 \%)$ e em muitos países da América Latina ${ }^{6}$, mas inferior ao existente na década de 2000 nos países da Europa ocidental. Essa presença feminina e suas consequências foram até o momento pouco estudadas. Enquanto a incorporação das mulheres à polícia vem sendo amplamente pesquisada na bibliografia internacional desde a década de 1970, há poucos trabalhos brasileiros sobre o tema. Como notado em estudo realizado pela Secretaria Nacional de Segurança Pública - Senasp (2013), embora crescente, a produção nacional sobre polícia e gênero é ainda formada por apenas três trabalhos de referência: Calazans (2003), Soares e Musumeci (2005) e Sadek (2003). A maioria dos estudos são resultantes de pesquisas de pós-graduação sobre as mulheres na Polícia Civil (Bahia e Ferraz, 2000; Sacramento, 2007; Silveira, 2009) e na Polícia Militar (Cappelle, 2006; Schactae, 2011; Moreira, 2011; Oliveira, 2012; Souza, 2009, 2014), que não se converteram em publicações nos principais periódicos brasileiros da área de ciências sociais.

Este artigo pretende contribuir para essa bibliografia através de análise de dados de survey realizado junto à Polícia Militar do Paraná (PMPR) (Ribeiro et al., 2012)7 para testar algumas hipóteses derivadas de perspectivas teóricas presentes na literatura internacional sobre polícia e gênero. A PMPR foi a segunda corporação militar brasileira a incorporar mulheres em seus quadros. Essa incorporação ocorreu em 1977 por meio da criação de uma divisão de policiamento feminino ${ }^{8}$. Em 2000, essa divisão foi extinta e as mulheres integradas a uma carreira policial única. Apesar de a unificação de quadros

\footnotetext{
${ }^{5}$ A exceção é a força policial paulista, que criou um corpo feminino de guardas civis já em 1955 . Esse corpo foi integrado na década de 1970 aos quadros da então recém-criada Polícia Militar do Estado de São Paulo (PMESP) (Soares e Musumeci, 2005).

${ }^{6}$ Com exceção do Uruguai, que tem padrões discrepantes do restante da América Latina (25,6\%), e do Chile, que tem o mesmo percentual de mulheres que o Brasil (13\%), as forças policiais dos demais países latinoamericanos pesquisados por Donadio (2009) apresentam percentuais de mulheres em torno de $10 \%$ do efetivo.

${ }^{7}$ A base de dados dessa pesquisa (Ribeiro et al., 2012) está disponível no site do Cesop, em Revista Opinião Pública, ao final da página do artigo (<https://www.cesop.unicamp.br/por/opiniao_publica/artigo/685>).

${ }^{8}$ Vale salientar que a PMPR foi fundada em 1854, portanto, seus portões foram abertos às mulheres apenas 123 anos depois da sua criação.
} 
representar um avanço no processo formal de incorporação das mulheres à polícia, estudos já realizados mostram que a plena integração feminina tende a encontrar obstáculos informais decorrentes do modo como os policiais veem o policiamento e o papel que homens e mulheres deveriam desempenhar dentro dele. A representação do policiamento como uma atividade arriscada de enfrentamento violento da criminalidade, combinada com a visão segundo a qual os homens são mais fortes e corajosos do que as mulheres, favorece a defesa da divisão sexual de funções dentro da polícia entre homens que deveriam se dedicar ao trabalho operacional de combate ao crime e mulheres que deveriam se dedicar ao trabalho administrativo e de cuidado. Assim, saber como os policiais veem o policiamento e a adequação dos sexos ao trabalho policial é fundamental para a compreensão da natureza das resistências e dos desafios existentes à integração das mulheres ao policiamento ostensivo.

O objetivo deste artigo é descobrir se ser homem ou mulher influencia (i) no grau de concordância dos membros da Polícia Militar do Paraná com a ideia de que a força física e a coragem são qualidades fundamentais à atividade policial; e (ii) na opinião de que os policiais masculinos são mais adaptados às atividades operacionais e as policiais femininas, às atividades de cuidado e assistência. Há, na literatura internacional, hipóteses distintas acerca das visões dos policiais sobre essas questões. Essas hipóteses estão relacionadas a três diferentes perspectivas teóricas que serão testadas neste artigo: as teorias sobre papéis de gênero; as teorias sobre socialização ocupacional; e as teorias sobre construção social de gênero.

O artigo está organizado da seguinte forma: A seção "Polícia e gênero: abordagens teóricas e descobertas empíricas" discute as teorias sobre papéis de gênero, socialização ocupacional e construção social de gênero. As hipóteses derivadas dessas teorias são apresentadas na seção "Hipóteses". Depois de descrever a metodologia do estudo em "Metodologia", a seção "Resultados" busca testar as hipóteses por meio de regressão logística. Os resultados encontrados na análise de regressão são debatidos na seção "Discussão". Por fim, em "Conclusão" são apresentados os apontamentos sobre os achados da pesquisa e suas implicações.

\section{Polícia e gênero: abordagens teóricas e descobertas empíricas}

A preocupação que move muitos dos estudos sobre polícia e gênero na bibliografia internacional é o entendimento das barreiras que impedem a plena integração das mulheres às organizações policiais (Martin, 1980; Heidensohn, 1992; Haarr, 1997; Holdaway e Parker, 1998; Martin e Jurik, 2006; Dick e Jankowicz, 2001; Brown, 2002; Dick e Cassell, 2004; Chan, Doran e Marel, 2010). A compreensão dessa questão passa pela análise das atitudes e visões dos policiais homens e das policiais mulheres sobre o policiamento e o papel que cada um deveria desempenhar dentro dele. Pelo menos três grandes perspectivas teóricas têm sido mobilizadas para explicar essas atitudes e visões: 
as teorias sobre papéis de gênero; as teorias sobre socialização ocupacional; e as teorias sobre construção social de gênero. As duas primeiras estão diretamente relacionadas, respectivamente, ao que Poteyeva e Sun (2009) chamaram de abordagem teórica da diferença e abordagem teórica da semelhança atitudinal entre gêneros na polícia. Já a terceira perspectiva pretende ser uma alternativa teórica às anteriores, especialmente às teorias sobre papéis de gênero.

As teorizações sobre papéis de gênero oferecem os fundamentos da abordagem da diferença. Essas teorizações sustentam que homens e mulheres tendem a ter visões diferentes sobre o policiamento. Essas diferenças, por sua vez, gerariam a concordância de que algumas atividades dentro da polícia devem ser desempenhadas por homens e outras por mulheres. Enquanto os homens dariam mais valor ao trabalho de combate ao crime e imposição coercitiva da lei, as mulheres dariam mais importância às atividades de manutenção da ordem e prestação de serviços, que ocupam a maior parte do tempo dos policiais - mediação de disputas, resolução de conflitos domésticos, orientações ao público, atendimento de vítimas, policiamento de trânsito e os demais trabalhos que ocorrem nas delegacias de polícia. Subjacente a essas atitudes está a visão dos homens de que as habilidades físicas que eles possuem os tornariam mais aptos do que as mulheres ao trabalho de imposição coercitiva da lei (Chu, 2013), que se sentiriam mais vocacionadas para as atividades de atendimento de vítimas, prevenção do crime e mediação de disputas que não envolvem violações claras da lei criminal. A preferência das mulheres por essas atividades estaria relacionada ao fato de elas serem socializadas desde a infância em papéis parentais e de cuidado (Worden, 1993; Poteyeva e Sun, 2009).

Uma das inspirações da abordagem da diferença é o trabalho de Gilligan (1982) sobre o desenvolvimento moral de pessoas jovens, referência importante no campo feminista e ponto de partida de diversos debates criminológicos sobre as atitudes e comportamentos de homens e mulheres. Gilligan sustenta que homens e mulheres se orientam por moralidades distintas. Os homens incorporam uma "moralidade da justiça", definida em termos de regras e direitos que ordenam as relações entre indivíduos autônomos; a justiça é aqui percebida como a imposição de regras iguais para todos. Já as mulheres subscrevem uma "moralidade do cuidado", concebendo a sociedade como uma rede interconectada e interdependente de relações pessoais na qual a justiça se associa ao ato de cuidar e proteger as pessoas e as relações entre elas. Gilligan (1982) atribui o desenvolvimento dessas moralidades principalmente às relações entre crianças e pais, mas estudos posteriores chamaram a atenção para outros processos, dentre os quais as experiências de cuidado que as mulheres têm com a maternidade, a socialização das mulheres em papéis domésticos e dos homens em papéis públicos, e a cultura patriarcal, que enfatiza a dependência das mulheres e o poder dos homens (Worden, 1993). Todas essas explicações oferecem os microfundamentos para a abordagem teórica das diferenças atitudinais de gênero dentro da polícia. As diferenças entre policiais homens e policiais mulheres resultariam da importação para dentro da polícia de visões de mundo associadas 
a gênero, que são geradas fora da organização policial e que contribuem para a aceitação da ideia de que homens e mulheres são diferentes e que, portanto, não estão em condições de desempenhar com igual eficiência as mesmas funções policiais. A pouca participação das mulheres em algumas atividades de policiamento decorreria dessa visão, que acaba por legitimar a divisão sexual de funções dentro da polícia.

As teorias da socialização ocupacional sustentam hipóteses contrárias às das teorias sobre as diferenças atitudinais de gênero e enfatizam que homens e mulheres tendem a ver o policiamento de forma parecida e que as mulheres demandam igual participação nas atividades policiais. Essas teorias estão por trás do que Poteyeva e Sun (2009) denominaram de abordagem da semelhança. O ponto de partida dessas perspectivas é a ideia de que as crenças e atitudes dos policiais são parte de uma cultura ocupacional que é forte o suficiente para suplantar eventuais visões de mundo decorrentes do modo como homens e mulheres são socializados antes da vida adulta. Essa cultura seria formada por um conjunto de símbolos, rituais e estórias que valorizam o combate físico, o perigo, a bravura e outros atributos socialmente reconhecidos como masculinos (Waddington, 1999; Reiner, 2004; Dick e Cassell, 2004; Brown, 2007). Explicações sobre os motivos pelos quais a cultura policial é permeada por esses elementos e reproduzida tanto por policiais masculinos quanto por policiais femininas podem ser encontradas nos trabalhos de Waddington (1999) e Dick e Cassell (2004).

Segundo Waddington (1999), a cultura policial glorifica a ação, a violência e os atributos associados ao universo masculino, promovendo o que o autor chama de "culto à masculinidade". Esse fenômeno seria uma resposta dos policiais a uma experiência ocupacional problemática. O trabalho policial é uma atividade entediante na qual a força física raramente é usada, mas essa possibilidade está sempre presente. Para Waddington, quando valorizam a violência, os policiais fazem o que outras profissões também fazem: celebram o que eles e muitos observadores consideram como o verdadeiro trabalho da polícia - a imposição da lei mediante a ameaça ou o uso da força física legítima que buscam monopolizar. Assim, o culto à masculinidade funcionaria para os policiais masculinos e para as policiais femininas como uma justificativa ideológica para a autoridade que eles precisam exercer sobre os cidadãos. Funcionaria também para conferir um senso de solidariedade entre os policiais da ponta, que estão submetidos ao poder dos supervisores de sancionar comportamentos em uma atividade amplamente discricionária na qual os limites entre o apropriado e o inapropriado nem sempre são claros. Em outros termos, valorizar a ação, a violência e o caráter duro do policiamento funcionaria como uma justificativa e uma válvula de escape para as pressões a que os policiais em geral estão submetidos em seu ambiente ocupacional e organizacional. Embora sofram com os efeitos adversos da representação do policiamento como uma atividade masculina de combate ao crime, as mulheres não desafiariam decisivamente essa representação. Para Waddington, as reclamações das mulheres contra a discriminação sexual estão mais relacionadas às barreiras que os homens impõem à sua participação nas atividades de aplicação coercitiva 
da lei - o verdadeiro trabalho policial, reconhecido como uma atividade de homens - do que ao modo como o policiamento é representado pela cultura policial.

Na mesma linha de Waddington (1999), Dick e Cassell (2004) utilizam a noção de "trabalho de identidade" (identity work) para sustentar que a construção e a reprodução do discurso do policiamento como gestão de conflitos oferecem aos policiais sentido e justificativa para uma experiência ocupacional constantemente sujeita ao escrutínio e à crítica do público e dos superiores hierárquicos. O discurso do policiamento como gestão de conflitos pode ser interpretado como um meio de os policiais resistirem subjetivamente às pressões a que estão submetidos no ambiente de trabalho. A concordância das mulheres com essa visão seria uma consequência do seu desejo de superar as barreiras impostas pelos homens e se integrar ao policiamento. Como observaram Dick e Cassell (2004), as mulheres não apenas precisam resistir ao escrutínio crítico da organização e do público em geral, mas também aos questionamentos dos colegas do sexo masculino em relação à sua adaptação a um trabalho que é considerado conflituoso, arriscado e pesado. Assim, consentir com as representações masculinas do policiamento seria uma forma de as mulheres afirmarem a sua identidade policial não apenas perante o público e os supervisores, mas também frente aos seus colegas de trabalho.

Pesquisas qualitativas realizadas nos EUA e no Reino Unido apoiam a hipótese de que as policiais mulheres dão grande importância à aplicação coercitiva da lei e reclamam participação nessas atividades (Westmarland, 2001; Heidensohn, 1992). Todavia, os estudos quantitativos a esse respeito apresentam resultados contraditórios (Poteyeva e Sun, 2009). Pesquisas como as de Worden (1993) nos Estados Unidos e de Sun e Wasileski (2010) na Eslováquia, por exemplo, não encontraram diferenças estatisticamente significativas entre policiais homens e policiais mulheres em relação ao apoio dado às funções de combate ao crime e imposição da lei. Mas essas diferenças foram encontradas no estudo que Sun (2003) realizou em uma força policial dos Estados Unidos, que descobriu que as mulheres possuem uma visão mais ampla que a dos homens sobre o policiamento, valorizando atividades outras que não a imposição da lei. Diferenças atitudinais entre homens e mulheres também foram encontradas na Ásia em relação à integração das mulheres ao policiamento. O estudo de Chu (2013) com policiais de Taiwan revelou, por exemplo, que as mulheres têm mais chances do que os homens de concordar com a ideia de que homens e mulheres não deveriam desempenhar as mesmas atividades, especialmente quando há perigo envolvido. Em outros termos, as policiais mulheres de Taiwan não apoiavam a sua total integração ao policiamento, referendando indiretamente a divisão sexual de funções dentro da polícia.

Como notaram Poteyeva e Sun (2009), os resultados divergentes das pesquisas quantitativas podem estar relacionados ao fato de elas trabalharem com conceitos amplos sobre o papel da polícia e diferentes formas de mensurá-lo. Mas é preciso notar que as divergências podem também estar ligadas ao fato de as atitudes dos(as) policiais sobre a sua ocupação, especialmente das mulheres, serem mais heterogêneas e mutáveis do que 
as teorias sobre as diferenças de gênero e as teorias sobre a socialização ocupacional supõem. Essas questões têm sido levadas em consideração por uma outra abordagem influente no campo dos estudos sobre polícia e gênero: a perspectiva da construção social de gênero. Essa abordagem também sustenta que os policiais homens valorizam o combate ao crime e resistem à participação das mulheres nessas funções, mas defende que a visão das policiais mulheres em relação ao policiamento e à divisão de funções policiais varia de acordo com o modo como elas "fazem gênero" e realizam escolhas em suas carreiras.

Martin (1996) é a autora mais influente dentro dessa perspectiva. Sua análise parte da ideia de Acker (1992) de que as ocupações não são neutras em termos de gênero, isto é, não são posições vazias a serem preenchidas pelas pessoas mais qualificadas. Ocupações como a de policial desenvolvem-se em organizações generificadas, que operam com ideologias, costumes e práticas que produzem e reproduzem desigualdades de gênero. No entanto, para Martin (1996), essas desigualdades não resultariam de processos de socialização que conformam papéis sociais distintos para homens e mulheres, como sustentam as teorias tradicionais sobre as diferenças de gênero. Valendo-se do trabalho seminal de West e Zimmerman (1987), Martin (1996) defende que as diferenças de gênero são construídas de forma dinâmica, relacional e contínua dentro da polícia e de outros espaços sociais. Assim, ela trabalha com a ideia de que gênero não é um atributo individual ou um papel aprendido em processos de socialização, mas uma construção que emerge em interações constantes, nas quais os indivíduos adotam atitudes e comportamentos que refletem ou expressam a sua participação em determinada categoria de sexo ${ }^{9}$.

Para Martin (1996), a ocupação policial é marcada pela lógica do sexismo. Seguindo Hunt (1990), a autora afirma que o mundo policial é atravessado por uma visão dualista que associa oposições estereotipadas de gênero (masculino/feminino) a símbolos organizacionais (rua/delegacia de polícia), assuntos e atividades de trabalho (combate ao crime/prestação de serviços e manutenção da ordem) e significados situacionais (público/doméstico; sujo/limpo). Os homens desvalorizam os polos associados ao universo feminino dessas dualidades e criam uma imagem idealizada do policiamento como algo violento, incerto e orientado para a ação de combate ao crime. Ao conceberem o policiamento como uma atividade perigosa que ocorre nas ruas, envolve embates físicos e requer força, coragem e senso prático para ser executado, eles promovem e se autoidentificam com o que Reuss-Ianni e Ianni (1983) chamaram de a "cultura do policial de rua". Já as atividades policiais não diretamente relacionadas ao combate ao crime, e as atividades de supervisão e de natureza administrativa que ocorrem no interior das unidades policiais são consideradas trabalhos femininos, valorizados apenas pela "cultura do policial administrativo", que enfrenta o desprezo dos policiais de rua (Reuss-Ianni e Ianni, 1983).

\footnotetext{
${ }^{9}$ O trabalho de West e Zimmerman (1987) inspira-se na etnometodologia de Garfinkel (1967) e está baseado no estudo de caso do transexual Agnes. A abordagem proposta parte de uma distinção entre sexo, categoria de sexo e gênero.
} 
Segundo Martin (1996), a oposição dos homens à integração das mulheres na ocupação policial decorre não apenas da percepção de que elas são fisicamente mais fracas. Essa oposição também está relacionada à natureza do trabalho policial, à cultura ocupacional e à maneira como esses elementos são usados para fazer gênero. A presença das mulheres no policiamento questionaria o único recurso superior dos homens (a força física) e os deixaria temerosos de ficar em desvantagem em um eventual confronto. Como acham que as mulheres não estão em condições de combater e controlar pessoas do sexo masculino, sentem-se desconfortáveis diante da possibilidade de serem protegidos pelas mulheres, situação que subverteria os estereótipos do homem protetor e da mulher frágil. Na percepção dos policiais homens, as mulheres também seriam mentalmente mais frágeis e pouco confiáveis nas situações de perigo, além de serem incapazes de impor respeito perante o público. Por isso é que muitos homens afirmam que patrulham de forma mais cautelosa e "menos eficaz" quando estão com parceiras. Martin (1996) defende ainda que a oposição dos homens à participação das mulheres no policiamento está relacionada a razões mais sutis e profundas. Ela afirma que as mulheres abalam a solidariedade no ambiente de trabalho na medida em que levantam "o espectro" de uma possível intimidade sexual entre os parceiros, promovendo a concorrência entre homens e criando lealdades competitivas. As mulheres também ameaçariam a máscara de desapego emocional usada por policiais do sexo masculino, expondo o fato de que a realidade do dia a dia do policiamento não gira em torno apenas do combate ao crime, mas envolve trabalho emocional e habilidades nas relações interpessoais. Além disso, a presença das mulheres inibiria o uso de linguagem chula, a prática de atividades sexuais ilícitas e o desfrute das vantagens que a masculinidade confere a eles durante o trabalho. Por último, Martin considera que o temor dos homens perante a presença das mulheres no policiamento também reflete uma preocupação mais profunda sobre quem tem o direito de gerenciar a lei e a ordem na sociedade, atribuições tradicionalmente associadas aos homens.

Diferentemente das teorias sobre papéis de gênero, que sustentam que as mulheres tendem a valorizar e a aceitar as funções policiais não associadas à imposição da lei, e diferentemente das teorias sobre socialização ocupacional, que afirmam que as mulheres tendem a valorizar tal qual os homens os aspectos masculinos da cultura policial e a reivindicar igual participação nas atividades de combate ao crime, essa perspectiva da construção social de gênero defende que essas posições são dinâmicas. Segundo Martin (1980), as atitudes das mulheres em relação ao policiamento e à divisão de funções dentro da polícia dependem de uma escolha que as mulheres fazem entre ser uma "policial mulher" ou ser uma "mulher policial". Como a cultura policial valoriza comportamentos associados ao universo masculino, Martin (1980) argumenta que as mulheres que ingressam na polícia se deparam com um dilema. Por um lado, espera-se que elas pensem e ajam como os seus colegas policiais homens. Por outro, espera-se e pressiona-se para que elas tenham atitudes e comportamentos considerados femininos. Assim, ao fazer 
gênero no trabalho as mulheres continuamente devem decidir quando e como agir como uma policial e quando e como agir como uma "dama" (Brown, 2002).

As circunstâncias nas quais as mulheres fazem essas escolhas foram analisadas por Chan, Doran e Marel (2010) em um estudo transversal e longitudinal de uma força policial da Austrália. Dois tipos de dados foram usados no estudo: dados de um painel de quatro rodadas envolvendo apenas policiais femininas que foram entrevistadas seis meses depois de entrarem na polícia (20 entrevistas), 18 meses depois (16 entrevistas), 24 meses depois (17 entrevistas) e de 9 para 10 anos depois (15 entrevistas); e dados de um estudo transversal com as 15 mulheres entrevistadas na última rodada do estudo longitudinal e mais 18 policiais homens no meio da carreira, somando ao todo 33 entrevistas. O estudo transversal serviu para classificar os indivíduos em três grupos: "fazendo gênero", "desfazendo gênero" e "fazendo e desfazendo gênero". O primeiro reunia policiais que pensavam que homens e mulheres não tinham as mesmas capacidades físicas e que, por isso, não deviam desempenhar as mesmas funções policiais. O segundo grupo era formado por indivíduos que rejeitavam qualquer tipo de tratamento diferenciado entre homens e mulheres, incluindo a divisão sexual de funções policiais. Por fim, o último grupo era formado por policiais que achavam que homens e mulheres são diferentes e trazem qualidades distintas para o policiamento, mas devem ser tratados igualmente como policiais. Chan, Doran e Marel (2010) descobriram que a maior parte dos policiais masculinos e femininos se enquadravam no grupo "fazendo gênero". Todavia, o estudo longitudinal mostrou que a posição das mulheres variou ao longo do tempo sob o efeito de fatores estruturais e conjunturais. Nos anos iniciais da carreira, a principal preocupação das mulheres era ser aceita dentro da polícia. Desfaziam gênero e buscavam afirmar a sua identidade como policiais, assimilando atitudes e valores típicos da cultura policial: valorizavam o trabalho nas ruas e criticavam o trabalho administrativo; minimizavam as diferenças entre policiais homens e policiais mulheres; e enfatizavam as distinções entre policiais e não policiais - o "nós" versus "eles" da cultura policial (Reiner, 2004). Mas, à medida que progrediam na carreira e quando se tornavam mães, as mulheres faziam gênero e passavam a aceitar o discurso das diferenças físicas entre homens e mulheres e a ideia de que a linha de frente do policiamento deveria ser ocupada pelos homens. Assim, a conclusão geral de Chan, Doran e Marel (2010, p. 443) foi que as mulheres tendem a ser favoráveis a uma espécie de divisão sexual do trabalho policial depois que se sentem seguras com a sua identidade policial e quando assumem responsabilidades parentais.

As três perspectivas teóricas descritas acima ainda não foram mobilizadas explicitamente por nenhum trabalho sobre polícia e gênero realizado no Brasil. A bibliografia nacional sobre o tema é relativamente incipiente e pouco dialogou com a literatura internacional. São poucos os estudos que analisaram as opiniões dos policiais militares brasileiros sobre o policiamento e a divisão do trabalho policial sob a perspectiva de gênero. Os mais destacados são os trabalhos de Calazans $(2003,2004)$, Soares e Musumeci (2005) e Souza (2014), cujas análises sobre as visões dos indivíduos policiais 
estão baseadas em dados qualitativos coletados na Brigada Militar do Rio Grande do Sul, na Polícia Militar do Rio de Janeiro e na Polícia Militar de São Paulo, respectivamente. Em sua pesquisa, Calazans $(2003,2004)$ mostrou que a Polícia Militar atuava como uma máquina de produção de subjetividades que utilizava o militarismo e a violência como dispositivos estratégicos para transformar homens e mulheres em policiais, impedindo a manifestação de qualquer forma de singularização feminina. As mulheres que ingressavam na polícia encontravam uma instituição na qual o sexo era fonte de status e poder. Os homens estavam estabelecidos e eram reconhecidos como representantes da tradição do militarismo e do policiamento ostensivo, que era identificado com o uso da força física. Já as mulheres novatas eram vistas como outsiders, com limitações naturais para desempenhar o policiamento ostensivo, que requeria atributos como coragem, força física e imposição de respeito. Segundo Calazans (2003, 2004), essas concepções prevalecentes sobre gênero e policiamento condicionavam o processo de inserção de homens e mulheres nos postos de trabalho da polícia. Enquanto os homens eram direcionados para as atividades de policiamento ostensivo e de comando, as mulheres eram direcionadas para subgrupos de trabalho ou mesmo para subtrabalhos dentro da organização. Dessa forma, configurava-se o que a autora chamou de processo de inclusão-exclusão-dominação das mulheres na polícia. Calazans não analisou como as mulheres se posicionavam diante desse processo, mas a afirmação de que a Polícia Militar é uma máquina de produção de subjetividades que impede qualquer processo de singularização parece aproximar as conclusões da autora da perspectiva teórica da socialização ocupacional.

Já os trabalhos de Soares e Musumeci (2005) e Souza (2014) chegaram a descobertas contraditórias em relação à visão dos indivíduos policiais sobre o policiamento, porém próximas ao preconizado pela perspectiva da construção social de gênero em relação à adequação dos policiais masculinos e femininos ao trabalho operacional. Os policiais de ambos os sexos estudados por Soares e Musumeci (2005) no Rio de Janeiro viam o policiamento como uma atividade orientada para o uso da força física e para o confronto com criminosos, ao passo que as policiais mulheres estudadas por Souza (2014) em São Paulo apresentavam uma visão mais ampla sobre o policiamento do que a dos policiais homens. Enquanto estes associavam o trabalho policial à promoção da segurança por meio do enfrentamento de ações criminosas, as mulheres davam mais destaque ao sentido de proteção e auxílio às pessoas. Em outros termos, os resultados encontrados por Soares e Musumeci (2005) em relação às visões sobre o policiamento eram convergentes com o preconizado pelas teorias sobre a socialização ocupacional, mas os resultados descobertos por Souza (2014) estavam mais de acordo com o previsto pelas teorias sobre papéis de gênero.

No que diz respeito à visão dos membros das polícias estudadas em relação à adequação dos gêneros ao trabalho operacional, Soares e Musumeci (2005) e Souza (2014) encontraram resultados convergentes. Em ambos os trabalhos, os policiais masculinos expressavam visões estereotipadas sobre policiamento e gênero que 
resultavam na defesa da ideia de que os homens são naturalmente mais adaptados ao trabalho operacional e as mulheres, mais adaptadas aos serviços administrativos e às atividades de relações públicas que visam humanizar as relações internas entre os policiais e as relações da polícia com a sociedade. Todavia, essas visões não eram reproduzidas de forma unânime entre as policiais mulheres. As policiais femininas entrevistadas por Soares e Musumeci (2005) frequentemente se dividiam entre a necessidade de se afirmar como iguais aos homens, demonstrando sua capacidade como policiais, e o desejo de garantir respeito ao que percebiam como sendo as suas especificidades - maior fragilidade física e emocional, o fato de engravidarem, terem que cuidar dos filhos etc. Dividiam-se então entre avaliações ambíguas situadas entre dois extremos: a que endossava os estereótipos de gênero e concebia o serviço interno como um lugar mais apropriado para as especificidades femininas; e a que negava qualquer diferença entre gênero e afirmava que homens e mulheres podiam realizar o policiamento igualmente. Souza (2014) também descobriu que, enquanto a divisão sexual de funções era amplamente aceita e preconizada por todos os policiais homens, as mulheres tinham uma posição mais diversa. Boa parte demandava o trabalho interno e/ou de relações públicas, a partir do entendimento de que ele oferecia oportunidades para que o perfil supostamente mais sensível, organizado e comunicativo do gênero feminino se manifestasse e para conciliar a profissão com as atividades de cuidado com a família. Outras apostavam no trabalho operacional no começo da carreira como estratégia de reconhecimento dentro da corporação, mas continuavam a representar o trabalho administrativo como uma oportunidade de se relaxarem da vigilância masculina e dos testes de competência a que eram submetidas nas ruas. Daí a conclusão de Souza (2014) de que os sentidos e interesses das mulheres em seu processo de inserção na Polícia Militar de São Paulo eram diversificados, com uma parte se espelhando nos comportamentos masculinos para serem reconhecidas no campo operacional, e outra reclamando o reconhecimento da "condição feminina" a partir da maternidade e da disposição reiterada para as ações que requerem maior sensibilidade e poder de comunicação.

As três pesquisas nacionais relatadas acima deram importantes contribuições para o campo de estudos sobre polícia e gênero no Brasil. A análise que será desenvolvida na sequência busca se somar a essas pesquisas por meio do estudo quantitativo das opiniões de uma amostra representativa de policiais da Polícia Militar do Paraná, que serão exploradas a partir de hipóteses derivadas da literatura internacional sobre polícia e gênero.

\section{Hipóteses}

As teorias sobre papéis de gênero, socialização ocupacional e construção social de gênero levam a hipóteses distintas em relação à (i) concordância de policiais homens e policiais mulheres com a visão segundo a qual o policiamento é uma atividade que requer 
atributos associados ao universo masculino, tais como coragem e força física; e (ii) opinião sobre quem seria mais preparado para o desempenho de funções operacionais arriscadas e funções de cuidado e assistência.

Da perspectiva das teorias sobre papéis de gênero, é possível derivar a hipótese de que homens e mulheres terão visões distintas sobre os atributos fundamentais ao policiamento. Essas diferenças estariam associadas a concepções morais construídas antes mesmo de os indivíduos adentrarem na polícia. Movidos por uma "moralidade da justiça" formada durante a infância e a juventude (Gilligan, 1982), os policiais homens tenderiam a ver o policiamento como uma atividade de imposição de normas contra indivíduos que infringem regras, portanto, como um trabalho que requer força física e coragem. Por outro lado, a "moralidade do cuidado", desenvolvida pelas mulheres ao serem socializadas em papéis maternos e de cuidado (Gilligan, 1982), faria com que elas tendessem a ver o policiamento como uma atividade na qual a sensibilidade e as habilidades interpessoais para lidar com indivíduos vulneráveis e para mediar disputas ficassem em primeiro plano. Como consequência dessas visões distintas sobre o policiamento, também podemos esperar que tanto os policiais homens quanto as policiais mulheres apoiarão a ideia de que os primeiros são mais vocacionados para as atividades operacionais que envolvem riscos e as segundas para as atividades de cuidado e assistência. Dessa forma, se as teorias sobre papéis de gênero estiverem corretas, devemos encontrar: (i) diferenças significativas entre policiais homens e policiais mulheres a respeito da importância atribuída à força física e à coragem no policiamento, com os homens valorizando esses atributos mais do que as mulheres; e (ii) nenhuma diferença de gênero em relação à opinião de que os homens são mais preparados para as atividades operacionais e de risco e as mulheres para as atividades que envolvem cuidado e assistência.

As teorias sobre a socialização ocupacional levam a hipóteses contrárias. Esperase que policiais de ambos os sexos compartilhem uma cultura ocupacional na qual a força física, o perigo e a coragem sejam considerados atributos fundamentais ao policiamento. Policiais homens valorizariam esses atributos para exaltar as peculiaridades e dificuldades do seu trabalho frente ao olhar crítico do público e dos superiores hierárquicos. As mulheres fariam o mesmo, mas não apenas para afirmar a sua identidade policial perante o público e supervisores; valorizariam o uso da força e a coragem também para fortalecer a sua identidade profissional perante os colegas de trabalho homens. Estes tenderiam a concordar com a ideia de que o policiamento operacional deve ser controlado pelos homens porque é uma atividade arriscada e conflituosa que requer coragem e capacidades físicas que as mulheres não detêm a contento, razão por que elas se sairiam melhor nas atividades policiais que envolvem cuidado e assistência. Essas atitudes masculinas de restrição à participação feminina nas atividades operacionais e arriscadas seriam rechaçadas pelas policiais mulheres, que demandariam igual participação no policiamento das ruas por se sentirem tão preparadas quanto os homens. Assim, se as teorias da socialização ocupacional estiverem corretas, devemos encontrar: (i) nenhuma diferença 
significativa entre policiais homens e policiais mulheres a respeito da importância atribuída à força física e à coragem no policiamento; e (ii) diferenças em relação à opinião de que os homens são mais preparados para as atividades operacionais e de risco e as mulheres para as atividades que envolvem cuidado e assistência, com os homens tendendo a concordar com essas visões mais do que as mulheres.

Por fim, se as teorias sobre a construção social de gênero estiverem corretas, devemos encontrar resultados que irão variar em função da posição que as policiais mulheres ocupam na carreira policial e em função de elas terem ou não responsabilidades parentais. Essa perspectiva sustenta que os policiais homens tenderão a valorizar a força física e a coragem e tenderão a ter atitudes de resistência à participação das mulheres no policiamento operacional. Todavia, considera que a visão das policiais mulheres sobre essas questões irá variar. Mulheres que estão no início da carreira policial e mulheres sem filhos tenderiam a considerar que a força física e a coragem são fundamentais para o policiamento e a rejeitar a ideia de que os homens são mais preparados para o trabalho operacional e de risco e as mulheres, para as atividades assistenciais e de cuidado. Assim, a partir da perspectiva que pensa gênero como uma construção social constante, é possível hipotetizar que (i) policiais mulheres em estágios mais avançados da carreira ou com filhos tenderão a atribuir menor importância à força física e à coragem no policiamento do que as mulheres no início da carreira e sem filhos, assumindo assim uma posição diferente da dos homens; (ii) policiais mulheres em estágios mais avançados da carreira ou com filhos tenderão a concordar mais com a visão segundo a qual os homens são mais preparados para as atividades operacionais e de risco e as mulheres para as atividades que envolvem cuidado e assistência do que as mulheres no início da carreira e sem filhos, assumindo assim posição semelhante à dos homens.

\section{Metodologia}

Os dados analisados na próxima seção são provenientes da pesquisa "Direitos humanos, igualdade de gênero e ação policial da Polícia Militar do Paraná" (Ribeiro et al., 2012). O objetivo da pesquisa foi captar as orientações subjetivas dos membros da Polícia Militar paranaense sobre direitos humanos e gênero. Para isso, foi realizado um survey com os indivíduos policiais da ativa, que, no momento da confecção do plano amostral (março de 2012), compunham um efetivo de 16.267 policiais, $92 \%$ dos quais eram homens e $8 \%$, mulheres. Considerando um erro amostral de $4 \%$ e um nível de confiança de $95 \%$, foi sorteada uma amostra com 600 policiais por meio da técnica de conglomerado em dois estágios: no primeiro foram selecionadas as unidades administrativas de policiamento e no segundo, os indivíduos policiais.

Na parte relativa à temática de gênero, uma série de afirmações foram formuladas para captar percepções e atitudes dos indivíduos a respeito de características ou atributos sexuais da atividade policial militar. As pessoas entrevistadas eram incentivadas a se 
posicionar a respeito de cada uma delas em uma escala de concordância que comportava as alternativas "discorda muito", "discorda", "concorda" e "concorda muito". Entre essas afirmações, selecionamos cinco, que representariam as percepções que se relacionam às hipóteses explicitadas anteriormente: 1) "A força física e a coragem são qualidades fundamentais para o desempenho da atividade policial"; 2) "O homem tem um melhor desempenho no serviço operacional por ser mais forte e corajoso que a mulher"; 3) "O policial masculino lida melhor com ocorrências de risco"; 4) "A policial feminina lida melhor com ocorrências de cuidado e assistência"; 5) "Considerando que você trabalhe ou trabalhasse na atividade operacional, é preferível trabalhar com policiais masculinos".

Para tornar mais compreensíveis os resultados dos modelos multivariados, optamos por recodificar as escalas distinguindo apenas respostas concordantes das discordantes, convertendo as cinco variáveis em dicotômicas. A partir desse procedimento, as medidas foram inseridas como dependentes em modelos de regressão logísticos binários, com o objetivo de estimar impactos de alguns atributos sobre a razão de chance de concordância. Coerentemente com as hipóteses de interesse da pesquisa, foram incluídos como preditores o sexo e os perfis produzidos pela combinação da idade e da declaração de maternidade das policiais mulheres. Assim, foram gerados quatro perfis para serem contrastados nos modelos com a condição de "homem": mulheres jovens; mulheres maduras ${ }^{10}$; mulheres com filhos; mulheres sem filhos. Além desses preditores, foram também adicionadas variáveis discretas relativas ao tipo de atividade (operacional ou administrativa) e ao grupo hierárquico (oficial ou praça). As categorias de referência para essas duas últimas variáveis são, respectivamente, "operacional" e "oficial", portanto, as estimativas se referem ao efeito de atuar na atividade fim, em contraste com a atuação em atividades administrativas, e ao impacto da condição de oficial (subtenente, tenente, capitão, major e tenente coronel) em oposição à de praça (soldado, cabo e sargento).

Nas Tabelas de 1 a 5 são reportados sempre os exponenciais de $B$ e, entre parênteses, o erro-padrão. Os níveis de significância são representados por asteriscos ao lado dos exponenciais.

\section{Resultados}

A Tabela 1 indica que não existem diferenças estatisticamente significativas entre homens e mulheres no que diz respeito à concordância com a afirmação de que "A força física e a coragem são qualidades fundamentais para o desempenho da atividade policial". A única variável com efeito nesses modelos iniciais foi a idade, com impacto idêntico nos Modelos 1 e 3. Nessas duas equações, para cada acréscimo de unidade de idade (anos de vida), a chance de concordar com a afirmação diminui em 3,5\%. Ainda que esse efeito

\footnotetext{
10 Para a composição dos grupos de "mulheres jovens" e "mulheres maduras", consideramos a idade média das policiais mulheres no momento em que a pesquisa foi realizada: 36 anos. Os grupos foram compostos da seguinte forma: $\leq 36$ = "mulher jovem"; e > 36 = "mulher madura".
} 
possa parecer reduzido, é preciso destacar que essa variável é contínua e comporta valores entre 20 e 59, o que torna o impacto cumulativo bastante relevante. Esse resultado, portanto, indica um efeito geracional, com os mais jovens apresentando níveis mais elevados de concordância.

Tabela 1

Análise de regressão para a pergunta "A força física e a coragem são qualidades fundamentais para o desempenho da atividade policial"

\begin{tabular}{|l|l|c|c|c|}
\hline Variáveis & \multicolumn{1}{|c|}{ Preditores } & Modelo 1 & Modelo 2 & Modelo 3 \\
\hline \multirow{5}{*}{ Explicativas } & Homens & $\begin{array}{c}1,43 \\
(, 328)\end{array}$ & - & - \\
\cline { 2 - 5 } & Mulheres jovens & - & $\begin{array}{c}1,68 \\
(, 379)\end{array}$ & - \\
\cline { 2 - 5 } & Mulheres maduras & - & $\begin{array}{c}2,09 \\
(, 668)\end{array}$ & - \\
\cline { 2 - 5 } & Mulheres sem filhos & - & - & $\begin{array}{c}1,51 \\
(, 441)\end{array}$ \\
\cline { 2 - 5 } & Mulheres com filhos & - & - & $\begin{array}{c}1,13 \\
(, 628)\end{array}$ \\
\cline { 2 - 5 } & Idade & $\begin{array}{c}965 * * \\
(, 012)\end{array}$ & - & $\begin{array}{c}, 965 * \\
(, 012)\end{array}$ \\
\cline { 2 - 5 } & Operacional & $\begin{array}{c}1985 \\
(, 255)\end{array}$ & $\begin{array}{c}1,08 \\
(, 250)\end{array}$ & $\begin{array}{c}992 \\
(, 257)\end{array}$ \\
\cline { 2 - 5 } & Oficial & $\begin{array}{c}1,254 \\
(409)\end{array}$ & $\begin{array}{c}1,34 \\
(, 406)\end{array}$ & $\begin{array}{c}1,26 \\
(, 409)\end{array}$ \\
\cline { 2 - 5 } & \% de acerto Bloco 0 & 59 & 59,3 & 60,7 \\
\hline & $\%$ de acerto Bloco 1 & 60,2 & 59,3 & 60,7 \\
\hline
\end{tabular}

Fonte: Elaboração própria com base em Ribeiro et al. (2012).

Nota: **sig. $>, 001 ; *$ sig. $>0,05$.

Algo distinto ocorre quanto à afirmação "O homem tem um melhor desempenho no serviço operacional por ser mais forte e corajoso que a mulher" (Tabela 2). No Modelo 1, como previsto pela perspectiva da socialização ocupacional, ser homem aumenta em $169 \%$ a chance de concordância. Quando passamos para o Modelo 2, ao contrário do predito pelas teorias sobre construção social de gênero, verificamos que as mulheres jovens (36 anos ou menos) têm probabilidade de concordância $124 \%$ maior do que os homens. 
Tabela 2

Análise de regressão para a pergunta "O homem tem um melhor desempenho no serviço operacional por ser mais forte e corajoso que a mulher"

\begin{tabular}{|c|c|c|c|c|}
\hline Variáveis & Preditores & Modelo 1 & Modelo 2 & Modelo 3 \\
\hline \multirow{5}{*}{ Explicativas } & Homens & $\begin{array}{c}2,69 * * \\
(, 351) \\
\end{array}$ & - & - \\
\hline & Mulheres jovens & - & $\begin{array}{l}2,24^{*} \\
(, 403) \\
\end{array}$ & - \\
\hline & Mulheres maduras & - & $\begin{array}{c}, 51 \\
(, 760)\end{array}$ & - \\
\hline & Mulheres sem filhos & - & - & $\begin{array}{c}1,57 \\
(, 452)\end{array}$ \\
\hline & Mulheres com filhos & - & - & $\begin{array}{c}29 \\
(, 718)\end{array}$ \\
\hline \multirow{5}{*}{ Controles } & Idade & $\begin{array}{c}99 \\
(, 011)\end{array}$ & - & $\begin{array}{c}\text {,99 } \\
(, 011)\end{array}$ \\
\hline & Operacional & $\begin{array}{c}1,03 \\
(, 253)\end{array}$ & $\begin{array}{c}1,02 \\
(, 251)\end{array}$ & $\begin{array}{c}198 \\
(, 258)\end{array}$ \\
\hline & Oficial & $\begin{array}{l}751 \\
(397) \\
\end{array}$ & $\begin{array}{c}, 75 \\
(, 395) \\
\end{array}$ & $\begin{array}{c}173 \\
(, 396) \\
\end{array}$ \\
\hline & $\%$ de acerto Bloco 0 & 55,6 & 55,9 & 56 \\
\hline & $\%$ de acerto Bloco 1 & 59,3 & 59,1 & 56 \\
\hline
\end{tabular}

Fonte: Elaboração própria com base em Ribeiro et al. (2012). Nota: $* *$ sig. $>, 001 ; *$ sig. $>0,05$.

Sobre a afirmação "Considerando que você trabalhe ou trabalhasse na atividade operacional, é preferível trabalhar com policiais masculinos" (Tabela 3), o Modelo 1 indica que, conforme previsto pelas teorias sobre papéis de gênero, ser homem ou mulher não faz diferença. Por outro lado, no Modelo 2 os dados são consistentes com os anteriores em relação à não comprovação das teorias sobre construção social de gênero: as mulheres jovens ( 36 anos ou menos) têm uma chance $18 \%$ maior do que os homens de concordar com a ideia de que é preferível trabalhar com homens nas atividades operacionais. 
Tabela 3

Análise de regressão para a pergunta "Considerando que você trabalhe ou trabalhasse na atividade operacional, é preferível trabalhar com policiais masculinos"

\begin{tabular}{|c|c|c|c|c|}
\hline Variáveis & Preditores & Modelo 1 & Modelo 2 & Modelo 3 \\
\hline \multirow{5}{*}{ Explicativas } & Homens & $\begin{array}{c}1,45 \\
(, 372) \\
\end{array}$ & - & \\
\hline & Mulheres jovens & - & $\begin{array}{l}1,18^{*} \\
(, 550) \\
\end{array}$ & \\
\hline & Mulheres maduras & - & $\begin{array}{c}699 \\
(, 656)\end{array}$ & \\
\hline & Mulheres sem filhos & - & - & $\begin{array}{c}97 \\
(, 461)\end{array}$ \\
\hline & Mulheres com filhos & - & - & $\begin{array}{c}144 \\
(, 639) \\
\end{array}$ \\
\hline \multirow{5}{*}{ Controles } & Idade & $\begin{array}{c}1,00 \\
(, 011)\end{array}$ & $\begin{array}{l} \\
-\end{array}$ & $\begin{array}{c}1,00 \\
(, 012) \\
\end{array}$ \\
\hline & Operacional & $\begin{array}{c}, 91 \\
(, 261)\end{array}$ & $\begin{array}{c}, 89 \\
(, 258)\end{array}$ & $\begin{array}{c}187 \\
(, 265)\end{array}$ \\
\hline & Oficial & $\begin{array}{c}1,35 \\
(, 420) \\
\end{array}$ & $\begin{array}{c}1,35 \\
(, 419) \\
\end{array}$ & $\begin{array}{c}1,31 \\
(, 420) \\
\end{array}$ \\
\hline & $\%$ de acerto Bloco 0 & 60,3 & 59,9 & 61,2 \\
\hline & $\%$ de acerto Bloco 1 & 60,3 & 62 & 61,2 \\
\hline
\end{tabular}

Fonte: Elaboração própria com base em Ribeiro et al. (2012).

Nota: *sig. $>0,05$.

Como previsto pela perspectiva da socialização ocupacional, no Modelo 1 da Tabela 4, ser homem aumenta em $231 \%$ a chance de concordar com a afirmação "O policial masculino lida melhor com ocorrências de risco". Aqui os resultados também contradizem as predições das teorias sobre construção social de gênero, já que no Modelo 2 "mulheres jovens" têm uma chance 144\% maior de concordância e no Modelo 3 "mulheres sem filhos" têm probabilidade de concordância elevada em $172 \%$, sempre considerando a comparação com homens. Ou seja, o efeito é contrário ao predito pelas teorias sobre construção social de gênero. 
Tabela 4

Análise de regressão para a pergunta "O policial masculino lida melhor com ocorrências de risco"

\begin{tabular}{|l|l|c|c|c|}
\hline Variáveis & \multicolumn{1}{|c|}{ Preditores } & Modelo 1 & Modelo 2 & Modelo 3 \\
\hline \multirow{5}{*}{ Explicativas } & Homens & $\begin{array}{c}3,31 * * \\
(, 351)\end{array}$ & - & - \\
\cline { 2 - 5 } & Mulheres jovens & - & $\begin{array}{c}2,44 * \\
(, 382)\end{array}$ & - \\
\cline { 2 - 5 } & Mulheres maduras & - & $\begin{array}{c}, 22 \\
(, 848)\end{array}$ & - \\
\cline { 2 - 5 } & Mulheres sem filhos & - & - & $\begin{array}{c}2,72 * \\
(, 447)\end{array}$ \\
\cline { 2 - 5 } & Mulheres com filhos & - & - & $\begin{array}{c}, 65 \\
(, 659)\end{array}$ \\
\hline \multirow{5}{*}{ Controles } & Idade & $\begin{array}{c}1,02 \\
(, 012)\end{array}$ & - & $\begin{array}{c}1,02 \\
(, 012)\end{array}$ \\
\cline { 2 - 5 } & Operacional & $\begin{array}{c}1,21 \\
(, 262)\end{array}$ & $\begin{array}{c}1,08 \\
(, 259)\end{array}$ & $\begin{array}{c}1,18 \\
(, 265)\end{array}$ \\
\cline { 2 - 5 } & Oficial & $(78$ &, 74 &, 77 \\
$(, 402)$ & $(, 400)$ & $(, 402)$ \\
\hline & $\%$ de acerto Bloco 0 & 65,1 & 65,0 & 65,1 \\
\hline & $\%$ de acerto Bloco 1 & 68,3 & 68,1 & 68,2 \\
\hline
\end{tabular}

Fonte: Elaboração própria com base em Ribeiro et al. (2012).

Nota: **sig. >,001; *sig. $>0,05$.

Sobre a última afirmação, "A policial feminina lida melhor com ocorrências de cuidado e assistência", como esperado a partir das teorias sobre papéis de gênero, não há diferenças entre homens e mulheres. As evidências também não dão sustentação às teorias sobre construção social de gênero, pois nenhum dos preditores teve efeito.

Tabela 5

Análise de regressão para a pergunta "A policial feminina lida melhor com ocorrências de cuidado e assistência"

\begin{tabular}{|c|c|c|c|c|}
\hline Variáveis & Preditores & Modelo 1 & Modelo 2 & Modelo 3 \\
\hline \multirow{5}{*}{ Explicativas } & Homens & $\begin{array}{c}1,15 \\
(, 334)\end{array}$ & - & - \\
\hline & Mulheres jovens & - & $\begin{array}{c}783 \\
(, 610) \\
\end{array}$ & - \\
\hline & Mulheres maduras & - & $\begin{array}{l}583 \\
(, 705)\end{array}$ & - \\
\hline & Mulheres sem filhos & - & - & $\begin{array}{c}1,09 \\
(, 461)\end{array}$ \\
\hline & Mulheres com filhos & - & - & $\begin{array}{c}, 90 \\
(, 639) \\
\end{array}$ \\
\hline \multirow{5}{*}{ Controles } & Idade & $\begin{array}{c}1,02 \\
(, 012)\end{array}$ & - & $\begin{array}{c}1,01 \\
(, 012)\end{array}$ \\
\hline & Operacional & $\begin{array}{c}1,14 \\
(, 260)\end{array}$ & $\begin{array}{c}1,14 \\
(, 256) \\
\end{array}$ & $\begin{array}{c}1,13 \\
(, 263)\end{array}$ \\
\hline & Oficial & $\begin{array}{r}903 \\
(404) \\
\end{array}$ & $\begin{array}{c}190 \\
(, 403)\end{array}$ & $\begin{array}{c}190 \\
(, 405)\end{array}$ \\
\hline & $\%$ de acerto Bloco 0 & 63,7 & 63,6 & 63,7 \\
\hline & $\%$ de acerto Bloco 1 & 63,7 & 63,3 & 63,7 \\
\hline
\end{tabular}

Fonte: Elaboração própria com base em Ribeiro et al. (2012). 


\section{Discussão}

Os resultados apresentados anteriormente indicam uma realidade complexa na qual estão presentes evidências que se enquadram tanto nas expectativas derivadas das teorias sobre papéis de gênero quanto nas predições associadas às teorias sobre socialização ocupacional. As hipóteses relacionadas às teorias que pensam o gênero como uma construção social constante não encontraram apoio nos dados.

As opiniões prevalecentes entre homens e mulheres de que as policiais femininas lidam melhor com ocorrências de cuidado e assistência e de que é preferível realizar o policiamento operacional com policiais masculinos podem ser consideradas condizentes com as hipóteses derivadas das teorias sobre papéis de gênero. Essas teorias defendem que a socialização em papéis de gênero antes da entrada na polícia faz com que as mulheres desenvolvam uma moralidade do cuidado e os homens uma moralidade da justiça (Gilligan, 1982). A importação dessas moralidades para dentro da polícia acabaria por gerar apoio à divisão sexual de funções policiais baseada na ideia de que as policiais femininas são mais preparadas para as atividades que envolvem cuidado e os policiais masculinos para as atividades que demandam coragem e força física (Worden, 1993; Poteyeva e Sun, 2009). Se levarmos em conta a concordância de ambos os sexos com a afirmação de que as mulheres lidam melhor com ocorrências de cuidado e assistência e se interpretarmos a preferência da maioria dos indivíduos policiais pelo trabalho operacional ao lado de policiais masculinos como um indicativo de reconhecimento do desempenho superior dos homens nessas atividades, poderíamos inferir que há dentro da Polícia Militar do Paraná apoio generalizado à divisão sexual de funções entre homens, dedicados ao policiamento operacional de risco, e mulheres, dedicadas às atividades policiais que envolvem cuidado e assistência.

Ocorre que esse apoio à divisão sexual de funções não se sustenta a partir do posicionamento dos membros da Polícia Militar paranaense em relação às demais questões. Policiais masculinos e policiais femininas têm posicionamentos distintos em relação à afirmação de que o homem tem um melhor desempenho no serviço operacional por ser mais forte e corajoso do que a mulher. Também têm posicionamentos distintos em relação à afirmação de que o policial masculino lida melhor com ocorrências de risco. Em ambos os casos, ser homem aumenta significativamente as chances de concordar com essas afirmações ao passo que ser mulher diminui essas chances. Assim, esses resultados não dão sustentação às hipóteses derivadas das teorias sobre papéis de gênero e sim às hipóteses relacionadas às teorias sobre socialização ocupacional. Para essas teorias, a ocupação policial gera uma cultura policial que valoriza um conjunto de atributos associados ao universo masculino, entre os quais a coragem e a força física (Waddington, 1999; Reiner, 2004; Brown, 2007). Esses atributos seriam valorizados tanto pelos policiais homens quanto pelas policiais mulheres como forma de engrandecer o trabalho policial frente às desconfianças da sociedade e de superiores hierárquicos (Waddington, 1999). 
Entre as mulheres, essa valorização também seria uma forma de afirmação perante os colegas de trabalho homens, que as consideram pouco preparadas para o trabalho operacional que envolve risco (Dick e Cassell, 2004). Daí a tendência de os homens concordarem e de as mulheres discordarem das afirmações de que os policiais masculinos são mais preparados do que as policiais femininas para o trabalho operacional e a centralidade atribuída por ambos os sexos à força física e à coragem no policiamento. Os resultados gerais são então ambíguos do ponto de vista da corroboração das hipóteses derivadas das teorias sobre papéis de gênero e das hipóteses relacionadas às teorias sobre socialização ocupacional.

Mas essa ambiguidade está alinhada com as descobertas dos estudos qualitativos sobre polícia e gênero realizados no Brasil. Soares e Musumeci (2005) já haviam notado que a integração das mulheres à Polícia Militar do Rio de Janeiro por meio da criação de uma carreira policial única, aliada à persistência de barreiras informais para impedir a participação feminina no policiamento operacional, criava uma situação que contribuía para gerar atitudes ambíguas nas mulheres, que frequentemente se dividiam entre "a necessidade de se afirmar como iguais aos homens, demonstrando sua capacidade como policiais, e ao mesmo tempo garantir o respeito às suas singularidades" (Soares e Musumeci, 2005, p. 179). Esse posicionamento feminino diverso também foi detectado pelo trabalho de Souza (2014), que descobriu que uma parte das mulheres buscava se espelhar nos comportamentos masculinos como forma de obter reconhecimento no policiamento operacional, enquanto outra almejava o reconhecimento da condição feminina e a disposição para as atividades que demandavam maior sensibilidade e capacidade de comunicação.

\section{Conclusão}

Quais as implicações das opiniões reveladas pela pesquisa para a plena integração das mulheres à Polícia Militar do Paraná? Os dados sugerem que a participação das mulheres em atividades que envolvem cuidado e assistência não é objeto de discordância e está consolidada dentro da corporação militar paranaense. Mas o mesmo não se dá em relação à participação das mulheres nas atividades operacionais arriscadas e que são percebidas como ações que requerem coragem e força física. Os homens tendem a desaprovar a participação das mulheres nessas atividades com base no argumento de que elas teriam menos atributos demandados para o policiamento operacional. Em uma ocupação dominada por homens, essa visão é decisiva, já que é da percepção de mundo dos policiais que nascem as atitudes e os comportamentos que impedem a participação das mulheres no policiamento operacional. Já as mulheres tendem a discordar da ideia de que elas têm um desempenho inferior ao dos homens no serviço operacional, indicando assim haver na Polícia Militar do Paraná resistências aos obstáculos informais criados para a plena integração das mulheres ao policiamento. Worden (1993) já havia chamado a 
atenção para o fato de que, em contextos nos quais um grupo tenta excluir outro da igual participação em determinadas atividades ou em uma determinada cultura, é esperado que os grupos excluídos reajam e expressem percepções e atitudes de resistência à exclusão imposta pelos grupos dominantes. Os dados analisados parecem se ajustar bem a essa ideia.

Interessante notar que as resistências das mulheres à exclusão do policiamento operacional parecem não colocar em xeque a visão masculinizada do policiamento. Estudos realizados desde a década de 1960 mostram que o grosso do trabalho policial é formado por atividades de prestação de serviços e manutenção da ordem que pouco demandam coragem e força física (Reiner, 2004, p. 163-171). As qualidades mais exigidas no policiamento são a sensibilidade e o cuidado para prestar serviços a pessoas em situações de vulnerabilidade (policiamento como serviço) e o senso de justiça para mediar e dirimir conflitos que não envolvem violações claras e inequívocas da lei criminal (policiamento como manutenção da ordem). Essas são qualidades socialmente associadas ao universo feminino e valorizá-las implicaria um possível fortalecimento da posição das mulheres nas atividades de policiamento. Mas isso não ocorre na Polícia Militar do Paraná. As mulheres valorizam a força física e a coragem no policiamento tal qual os homens e discordam da ideia de que apenas os primeiros estão aptos a realizar o policiamento por serem os portadores dessas qualidades. Em vez de representarem o policiamento como uma atividade associada a valores que poderiam favorecê-las, as mulheres reproduzem assim visões tradicionais sobre as atividades policiais e buscam se afirmar como iguais diante da desaprovação masculina à participação feminina no policiamento operacional. Ao se posicionarem dessa forma, elas buscam se colocar como iguais dentro de um contexto de representações sociais permeadas por valores masculinos em vez de questionarem o sentido desses valores para as atividades policiais. Em outros termos, aceitam a visão masculinizada do policiamento como uma atividade que depende fundamentalmente de força física e coragem e procuram se afirmar como iguais dentro desse universo masculinizado.

Esses resultados são importantes para a produção nacional sobre o tema. Apesar de utilizar uma metodologia de pesquisa quantitativa, os achados mais gerais deste artigo são convergentes com os encontrados em pesquisas qualitativas realizadas nas polícias militares do Rio de Janeiro (Soares e Musumeci, 2005) e São Paulo (Souza, 2014). Entretanto, essas convergências não autorizam a conclusão de que a cultura da Polícia Militar no Brasil é igualmente avessa à plena integração das mulheres em seus quadros. As organizações policiais brasileiras são diversas e pesquisas futuras deveriam levar isso em consideração, buscando realizar análises comparativas para testar a validade e a abrangência de teorias e hipóteses como as apresentadas neste artigo. Pesquisas futuras também deveriam considerar a realização de estudos longitudinais, apropriados para captar variações na maneira como homens e mulheres constroem gênero ao longo de suas carreiras. 


\section{Referências bibliográficas}

ACKER, J. "From sex roles to gendered institutions". Contemporary Sociology - American Sociological Association, vol. 21, no 5, p. 565-569, 1992.

BAhIA, M. C. A.; Ferraz, M. A. V. "Entre a exceção e a regra: a construção do feminino na polícia civil da Bahia". Organizações \& Sociedade, vol. 7, no 18, p. 25-40, 2000.

BRown, J. "European policewomen: a comparative research perspective". International Journal of the Sociology of Law, vol. 25, p. 1-19, 1997.

"'You can't have it both ways': being an officer and a lady (woman) in a male dominated occupation". In: Women and Policing Globally Conference, Canberra, 2002.

From cult of masculinity to smart macho: gender perspectives on police occupational culture. In: O'NeILL, M.; MARKS, M.; Singh, A-M. (eds.). Police occupational culture: new debates and directions. Oxford: Elsevier, 2007.

CALAZANS, M. E. "A constituição de mulheres em policiais: um estudo sobre policiais femininas na Brigada Militar do Rio Grande do Sul". Dissertação de Mestrado em Psicologia. Instituto de Psicologia. Programa de Pós-Graduação em Psicologia Social e Institucional. Universidade Federal do Rio Grande do Sul, Porto Alegre, 2003.

. "Mulheres no policiamento ostensivo e a perspectiva de uma segurança cidadã". São Paulo em Perspectiva, vol. 18, no 1, p. 142-150, 2004.

CAPPELle, M. C. A. "O trabalho feminino no policiamento operacional: subjetividade, relações de poder e gênero na 8 a Região de Polícia Militar de Minas Gerais". Tese de Doutorado em Administração. Centro de Pós-Graduação e Pesquisa em Administração, Universidade Federal de Minas Gerais, Belo Horizonte, 2006.

ChAn, J.; Doran, S.; MAREL, C. "Doing and undoing gender in policing". Theoretical Criminology, vol. 14 , p. 425-446, 2010.

CHU, D. "Gender integration in policing: a comparison of male and female police officers' perceptions in Taiwan". International Journal of Comparative and Applied Criminal Justice, vol. 37, no 2, p. 143157, 2013.

DICK, P.; CASSELL, C. "The position of policewomen: a discourse analytic study". Work Employment \& Society, vol. 18, no 1, p. 51-72, 2004.

Dick, P.; JANkowicz, A. D. "A social constructionist account of police culture and its influence on the representation and progression of female officers: a repertory grid analysis in a UK police force". Policing: An International Journal of Police Strategies and Management, vol. 24, no 2, p. 181-99, 2001.

DonAdio, M. La mujer en las instituciones armadas y policiales: resolución 1325 y operaciones de paz en América Latina. Buenos Aires: Red de Seguridad y Defensa de América Latina, 2009.

FBSP. Fórum Brasileiro de Segurança Pública. Anuário Brasileiro de Segurança Pública 2015 (online). São Paulo, 2015. Disponível em: <http://www.forumseguranca.org.br/produtos/anuario-brasileirode-seguranca-publica/9o-anuario-brasileiro-de-seguranca-publica>. Acesso em: 2 nov. 2016.

GARfinkel, H. Studies in ethnomethodology. Englewood Cliffs, NJ: Prentice-Hall, 1967.

Gilligan, C. In a different voice: psychological theory and women's development. Cambridge: Harvard University Press, 1982. 
HAARR, R. "Patterns of interaction in a police patrol bureau: race and gender barriers to integration". Justice Quarterly, vol. 14, p. 54-85, 1997.

HEIDENSOHN, F. Women in control? The role of women in law enforcement. Oxford: Clarendon Press, 1992.

HOLDAWAY, S.; PARKER, S. "Policing women police; uniform, patrol, promotion and representation in the CID". British Journal of Criminology, vol. 38, p. 40-60, 1998.

HUNT, J. "The logic of sexism among police". Women and Criminal Justice, vol. 1, p. 3-30, 1990.

MARTIN, S. Breaking and entering: policewomen on patrol. Berkeley: California University Press, 1980.

"Doing gender, doing police work: an examination of the barriers to the integration of women officers". In: Australian Institute of Criminology Conference First Australasian Women Police Conference. Sydney, 1996.

MARTIN, S. E.; JURIK, N. C. Doing justice, doing gender: women in law and criminal justice occupations. Thousand Oaks: Sage, 2006.

MoREIRA, R. "Sobre mulheres e polícias: a construção do policiamento feminino em São Paulo (19551964)". Tese de Doutorado em História. Universidade Federal de Santa Catarina, Florianópolis, 2011.

MoReIRA, R.; WolfF, C. "A ditadura militar e a face maternal da repressão". Dossiê Gênero, Feminismos e Ditadura, Revista Espaço Plural, vol. 10, no 29, p. 56-65, 2009.

OLIVEIRA, L. S. "'Teto de vidro': relações de gênero, relações de poder e empoderamento das mulheres na Polícia Militar". Tese de Doutorado em Ciências Sociais. Universidade Federal da Bahia, Salvador, 2012.

PoteYEVA, M.; SUn, I. "Gender differences in police officers' attitudes: assessing current empirical evidence". Journal of Criminal Justice, vol. 37, p. 512-522, 2009.

PRENZLER, T.; SinCLAIR, G. "The status of women police officers: an international review". International Journal of Law, Crime and Justice, vol. 41, n 2, p. 115-131, 2013.

ReIner, R. A política da polícia. São Paulo: Editora da Universidade de São Paulo, 2004.

ReUSS-IANNI, E.; IANNI, F. Street cops and management cops: the two cultures of policing. In: PUNCH, M. (ed.). Control in the police organization. Cambridge: MIT Press, 1983.

Ribeiro, E. et al. "Direitos humanos, igualdade de gênero e ação policial da Polícia Militar do Paraná". Universidade Estadual de Maringá, 2012.

SACRAmento, J. S. "Polícia e gênero: percepções dos delegados e delegadas da Polícia Civil do Rio Grande do Sul acerca da mulher policial". Dissertação de Mestrado em Sociologia. Universidade Federal do Rio Grande do Sul, Porto Alegre, 2007.

SADEk, M. T. Delegada: doutora e policial. In: SADEk, M.T. (org.). Delegados de polícia. São Paulo: Editora Sumaré, 2003.

SCHACTAE, A. M. "Farda e batom, arma e saia: a construção da Polícia Militar feminina no Paraná (1977-2000)". Tese de Doutorado em História. Universidade Federal do Paraná, Curitiba, 2011. 
SENASP. Mulheres nas instituições de segurança pública: estudo técnico nacional (online). Brasília: Ministério da Justiça/Secretaria Nacional de Segurança Pública (Senasp), 2013. Disponível em: http://www.justica.gov.br/sua-seguranca/seguranca-publica/analise-epesquisa/download/estudos_diversos/4mulheres-na-seguranca-publica.pdf. Acesso em: 12 fev. 2014.

Silveira, M. N. B. "As delegadas de polícia de São Paulo: profissão e gênero". Dissertação de Mestrado em Sociologia. Universidade Federal de São Carlos, São Carlos, 2009.

SoARes, B. M.; MusumeCI, L. Mulheres policiais: presença feminina na Polícia Militar do Rio de Janeiro. Rio de Janeiro: Civilização Brasileira, 2005.

SouzA, M. S. "'Elas não servem pra guerra': presença feminina e representações sociais de gênero da Polícia Militar de Sergipe". Monografia na área de Violência, Criminalidade e Políticas Públicas. Universidade Federal de Sergipe: São Cristóvão; Rede Nacional de Altos Estudos em Segurança Pública, 2009.

. "'Sou policial, mas sou mulher': gênero e representações sociais na Polícia Militar de São Paulo". Tese de Doutorado em Ciências Sociais. Instituto de Filosofia e Ciências Humanas. Universidade Estadual de Campinas, Campinas, 2014.

Sun, I. "Police officers' attitudes toward their role and work: a comparison of black and white officers". American Journal of Criminal Justice, vol. 28, p. 89-108, 2003.

SUN, I.; WASILESKI, G. "Gender differences in occupational attitudes among Slovak police". International Criminal Justice Review, vol. 20, no 3, p. 248-264, 2010.

WAdDington, P. A. J. "Police (canteen) sub-culture: an appreciation". The British Journal of Criminology, vol. 39, no 2, p. 287-309, 1999.

West, C.; Zimmerman, D. H. "'Doing gender'". Gender \& Society, vol. 1, nº 2, p. 125-151, 1987.

WestmARLAND, L. Gender and policing: sex, power and police culture. Cullompton: Willan, 2001.

WORDEN, A. P. "The attitudes of women and men in policing: testing conventional and contemporary wisdom". Criminology, vol. 31, no 2, p. 203-241, 1993.

\section{Abstract \\ Policing and gender: perceptions between military police officers from Paraná, Brazil}

Female integration into the police has been hampered by the way police officers represent policing and the role men and women should play in this activity. This article intends to contribute to the understanding of the nature of these representations and barriers. Does being a man or a woman condition the perception that physical strength and courage are key attributes for policing? Does it influence the view that male police officers are better equipped for operational activities and female police officers for care and assistance activities? The article analyzes these questions through multivariate quantitative analysis of data from a survey conducted in 2012 at the Military Police of the State of Paraná (PMPR), Brazil. The data indicate that men and women agree with the view that policing is an activity that demands physical strength and courage, but maintain different views on who is more able to perform operational activities. These results suggest considerable difficulties in integrating women into police operational activities.

Keywords: gender; military police; perception; survey research; Paraná 


\section{Resumen}

Policía y Género: percepciones entre policías militares paranaenses

La integración femenina a la policía viene encontrando obstáculos derivados de cómo policías representan el policiamiento y el papel que los hombres y las mujeres deberían desempeñar dentro de él. Este trabajo pretende contribuir al entendimiento de la naturaleza de esas representaciones y obstáculos. ¿Ser hombre o mujer condiciona la percepción de que fuerza física y coraje son atributos fundamentales para la policía? ¿Influencia la visión según cuál los policías masculinos son más preparados para las actividades operativas y las policías femeninas para las actividades de cuidado y asistencia? El artículo analiza estas cuestiones a través del análisis cuantitativo de datos de una encuesta de encuesta realizada en 2012 en la Policía Militar de Paraná. Los datos indican que hombres y mujeres concaten igualmente con la visión de que la policía es una actividad que demanda fuerza física y coraje, pero mantienen visiones distintas sobre quién es más apto para actuar en las actividades operacionales. Estos resultados sugieren dificultades considerables para la integración de las mujeres a las actividades operativas de la policía.

Palabras clave: género; policía militar; percepciones; investigación de survey; Paraná.

\section{Résumé}

Police et genre: perceptions de la police militaire à Paraná

L'intégration des femmes dans la police s'est heurtée à des obstacles liés à la manière dont celle-ci est représentée et au rôle que doivent jouer les hommes et les femmes. Ce document a pour objectif de contribuer à la compréhension de la nature de ces représentations et obstacles. Être un homme ou une femme conditionne-t-il la perception que la force physique et le courage sont des attributs essentiels du maintien de l'ordre? Cela influence-t-il l'opinion selon laquelle les policiers masculins sont mieux équipés pour les activités opérationnelles et les policières féminines pour les activités de soins et d'assistance? L'article analyse ces problèmes par le biais d'une analyse quantitative des données d'une enquête menée en 2012 dans la police militaire de Paraná. Les données indiquent que les hommes et les femmes sont également d'accord avec le point de vue selon lequel le maintien de I'ordre est une activité qui exige de la force physique et du courage, tout en maintenant des points de vue différents sur les personnes les plus aptes à exercer des activités opérationnelles. Ces résultats suggèrent des difficultés considérables d'intégration des femmes dans les activités opérationnelles de la police.

Mots-clés: genre; police militaire; les perceptions; enquête; Paraná

Artigo submetido à publicação em 26 de outubro de 2018. Versão final aprovada em 7 de janeiro de 2021.

Opinião Pública adota a licença Creative Commons CC-BY.

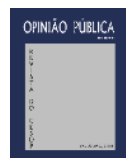

